\title{
A internacionalização das grandes empresas farmacêuticas nacionais: evolução, desafios e estratégias inovativas
}

Fernanda Steiner Perin Doutora em Economia pelo Instituto de Economia da Universidade Federal do Rio de Janeiro (IE/UFRJ). Pesquisadora do Grupo de Economia da Inovação (GEI/IE/UFRJ). E-mail: fernanda.steinerperin@gmail.com

Julia Paranhos Professora Adjunta do Instituto de Economia da Universidade Federal do Rio de Janeiro (IE/UFRJ). Coordenadora do Grupo de Economia da Inovação (GEI/IE/UFRJ). E-mail: juliaparanhos@,ie.ufrj.br

\section{Resumo}

O objetivo, neste trabalho, é analisar as características da internacionalização das grandes empresas farmacêuticas nacionais brasileiras. A partir de um estudo de múltiplos casos com oito empresas identificaram-se as formas de entrada, estratégias, vantagens competitivas e obstáculos encontrados na inserção internacional. Os resultados da pesquisa evidenciam as características comuns das empresas, em relação às vantagens competitivas e obstáculos, como também, dois padrões distintos de estratégias: a exploração de ativos e capacidades e o aprimoramento de ativos e capacidades no mercado internacional. As conclusões trazem contribuições à literatura de negócios internacionais de países em desenvolvimento, ao constatar que: i) as vantagens competitivas das empresas são construídas em momento anterior à internacionalização em relação a capacidade financeira e de adaptação ao ambiente competitivo doméstico; ii) as empresas seguem estratégias de aprimoramento tecnológico em países desenvolvidos como um atalho para superar suas debilidades inovativas; iii) os principais obstáculos para a internacionalização se referem ao aparato regulatório brasileiro.

Palavras-chave: Internacionalização de empresas de países em desenvolvimento, Indústria farmacêutica, Estratégia de inovação.

\begin{abstract}
The objective in this paper is to analyze the characteristics of the internationalization of the large Brazilian pharmaceutical companies. A study of multiple cases with eight companies was applied to identify the entry modes, strategies, competitive advantages and obstacles in the international insertion. The research results show the common characteristics of companies in relation to competitive advantages and obstacles, as well as two distinct patterns of strategies: the exploration of assets and capabilities and the improvement of assets and capabilities in the international market. The conclusions bring contributions to the international business of emerging countries literature, noting that: i) the competitive advantages of companies are built prior to internationalization in relation to financial capacity and adaptation to the domestic competitive environment; ii) companies follow strategies of technological improvement in
\end{abstract}


developed countries as a shortcut to overcome their innovative weaknesses; iii) the main obstacles to internationalization refer to the Brazilian regulatory apparatus.

Keywords: Internationalization of companies from developing countries, Pharmaceutical industry, Innovation strategy.

Área temática: Investimento Direto Estrangeiro e internacionalização de empresas.

JEL: F23, L65, O32.

\section{Introdução}

De modo geral, a indústria farmacêutica mundial é formada por empresas transnacionais centenárias originárias de países desenvolvidos (ETNs), empresas indianas e chinesas que vêm aumentando suas participações no mercado mundial, e por empresas de menor porte de outros países em desenvolvimento, como o Brasil. As ETNs atuam no segmento mais inovativo da indústria farmacêutica, investindo recursos elevados de Pesquisa \& Desenvolvimento (P\&D) para o desenvolvimento de novos medicamentos ${ }^{1}$ e empregando estratégias de inovação alinhadas às estratégias de internacionalização para poder acessar os conhecimentos dispersos globalmente (Mckelvey \& Orsenigo, 2001; Radaelli, 2006). A entrada das empresas asiáticas no setor foi percebida com a commoditização da produção de Insumos Farmacêuticos Ativos (IFAs), especialmente os insumos sem proteção de patentes produzidos pelas empresas chinesas, que ampliou a oferta mundial de matérias-primas a menores preços, e com a maior participação das empresas de medicamentos genéricos no mercado mundial, majoritariamente, provenientes da Índia (IEDI, 2016).

O mercado farmacêutico brasileiro é composto por empresas farmacêuticas nacionais, ETNs e laboratórios públicos. Estes últimos produzem exclusivamente para atender as demandas do Sistema Único de Saúde (SUS) e não participam do mercado varejista (Hasenclever et. al., 2008). A indústria farmacêutica brasileira foi criada a partir da dependência externa com pouco enfoque no desenvolvimento tecnológico nacional (Fialho, 2005). As ETNs ofertam medicamentos inovadores no mercado brasileiro, mas concentram os esforços tecnológicos em suas sedes (Carlsson, 2006). Alguns eventos recentes contribuíram para modificar o cenário farmacêutico brasileiro. O primeiro deles foi o Acordo TRIPS (Agreement on Trade-Related Aspects of Intellectual Property Rights), em 1994, instituindo a não discriminação setorial de patentes e o reconhecimento de patentes na área farmacêutica, o qual culminou na Lei de Propriedade Industrial (n 9.279/1996). Em 1999, a Agência Nacional de Vigilância Sanitária (Anvisa) foi criada (Lei $\mathrm{n}^{\circ}$ 9.782), ampliando as exigências regulatórias para comercialização de produtos farmacêuticos no país, e a Lei dos Genéricos ( $n^{\circ}$ 9.787) foi implementada, exigindo requisitos de

1 As grandes empresas farmacêuticas mundiais investem, em média, 20,9\% das receitas em P\&D (EvaluatePharma, 2018). 
bioequivalência e biodisponibilidade para os medicamentos e estabelecendo um novo segmento de atuação para as empresas. Além dessas medidas, a retomada das políticas industriais e tecnológicas, a partir de 2003, com incentivos para as atividades inovativas, estímulos à internacionalização de empresas e a priorização do setor farmacêutico, teve papel importante para o fortalecimento das empresas farmacêuticas nacionais (Hasenclever et al., 2018).

Estes eventos tiveram efeitos sobre a estrutura industrial farmacêutica do Brasil, levando as empresas farmacêuticas nacionais a construírem capacitações que lhes conferiram a proeminência no mercado brasileiro atual. Em 2017, seis entre as dez maiores empresas farmacêuticas brasileiras eram grandes empresas farmacêuticas nacionais (GEFN). Tais empresas se dedicam à produção medicamentos de menor valor agregado e baixo grau de inovação (medicamentos genéricos e genéricos de marca ${ }^{2}$ ). Entre 2003 e 2018, a taxa média de crescimento anual da venda de medicamentos genéricos no Brasil foi de $25 \%$, enquanto que para os demais medicamentos foi de 14\% (IQVA apud Sindusfarma, 2018).

No entanto, os desafios das GEFN ainda são muitos e ameaçam sua proeminência. Desde a abertura econômica dos anos 1990, a participação das ETNs no mercado doméstico cresce expressivamente e o déficit comercial do setor farmacêutico chegou a US\$ 5,3 bilhões em 2018, resultante das importações de IFAs (US\$ 1,9 bilhão) e de medicamentos prontos (US\$ 4,6 bilhão) (MDIC, 2019). Por outro lado, os medicamentos novos (38\%) e biológicos $(22 \%)$ têm maior importância no faturamento total do mercado farmacêutico brasileiro, sendo a participação na quantidade de produtos apenas de $18 \%$ e $4 \%$, respectivamente, o que demonstra que possuem maior valor agregado por empregarem mais inovações (Anvisa, 2017). Os medicamentos novos e os biológicos representam parcela significativa nas compras do SUS, de modo que o faturamento destes dois tipos de produtos em conjunto chega a $60 \%$ do total do mercado varejista e público.

A produção de medicamentos pela rota biológica, trajetória tecnológica atual da indústria farmacêutica (Tigre, Nascimento \& Costa, 2016), pode ser uma alternativa ao paradigma da rota química dominado pelas ETNs (Gomes, 2014), contudo, para entrar em segmentos de maior valor agregado é preciso que ocorra a construção de capacidades tecnológicas para desenvolvimento de inovação ${ }^{3}$. A taxa de empresas farmacêuticas inovadoras é maior que a da indústria de transformação, 36,3\% contra 52,2\%, em 2014. Apesar disso, a taxa de inovação das empresas farmacêuticas tem uma tendência declinante ao se comparar com 2008 (63,7\%) e 2011 (53,8\%). A queda no número de empresas que realizam investimento em inovação - 315 em 2008, 247 em 2011 e 212 em 2014 - reflete a concentração nos gastos com P\&D do setor farmacêutico em poucas grandes empresas com escala para implementá-los. As inovações da indústria farmacêutica brasileira são novidades em nível de empresa, tanto para produto quanto para

\footnotetext{
${ }^{2}$ Os medicamentos genéricos de marca são medicamentos similares na classificação da Anvisa. De acordo com a Resolução da Diretoria Colegiada (RDC) 200/2017 da Anvisa (2018), os medicamentos similares são idênticos ao medicamento de referência, sendo obrigatório passar pelo teste de bioequivalência, da mesma forma que o medicamento genérico, mas que adotam o nome da marca.

${ }^{3}$ No caso dos medicamentos obtidos pela rota biológica, a pouca experiência das empresas farmacêuticas nacionais na fabricação e inovação de insumos farmacêuticos impõe dificuldades à incorporação da produção de produtos biológicos. A natureza do processo produtivo de biofármacos envolve células vivas, dificilmente dissociada da formulação final do medicamento e requerem competências de maior complexidade tecnológica (Torres, 2015).
} 
processo, e há uma menor proporção em nível de mercado nacional e de mercado mundial. Em 2014, as empresas farmacêuticas brasileiras investiram, em média, 2,6\% (R\$ 1,4 bilhão) da sua receita líquida de vendas em atividades de $\mathrm{P} \& \mathrm{D}$, o que demonstra uma participação muito superior ao total da indústria de transformação ( $0,9 \%$ ou R \$ 22,1 bilhões) (IBGE, 2016), contudo, ainda muito aquém da média da indústria farmacêutica mundial (20,9\%) (EvaluatePharma, 2018).

É neste contexto que a internacionalização passou a fazer parte das estratégias de crescimento e de inovação das GEFN. A literatura sobre negócios internacionais evidencia que a internacionalização pode ser usada como uma oportunidade de encurtar o distanciamento tecnológico de empresas provenientes de países em desenvolvimento com empresas de países desenvolvidos. Deste modo, as empresas de países em desenvolvimento utilizam o mercado internacional como um atalho para adquirir capacidades tecnológicas ausentes no mercado doméstico (Luo \& Tung, 2007; Mathews, 2006), a luz do exemplo das empresas farmacêuticas indianas que internacionalizaram com o objetivo de fazer catching-up tecnológico (Kothari, Kotabe \& Murphy, 2013). Para tanto, estudos (Bonaglia \& Goldestein; Martin \& Javalgi, 2016; Aguilera, et al., 2017) mostram que as vantagens competitivas das empresas são construídas ainda no mercado doméstico em momento anterior à internacionalização. Sendo assim, o objetivo, neste trabalho, é analisar as características da internacionalização das GEFN, identificando às estratégias e formas de entrada no mercado internacional e as vantagens competitivas e obstáculos encontrados na inserção internacional.

\section{Metodologia}

Esta pesquisa é de natureza aplicada, com objetivos exploratório-descritivos e método hipotéticodedutivo. A abordagem da pesquisa tem caráter qualitativo utilizando o procedimento de estudos de múltiplos casos (Marconi \& Lakatos, 2016). A pesquisa foi elaborada em quatro etapas. Na primeira, foi realizada uma revisão de literatura para identificar as possíveis manifestações das características da internacionalização de empresas. A etapa seguinte consistiu na pesquisa dos atores para serem entrevistados na pesquisa de campo. Foram selecionadas GEFN pelo critério de pertencer à indústria farmacêutica (classificadas na Divisão 21 da Classificação Nacional de Atividade Econômica - CNAE), ser totalmente composta por capital nacional e ter estratégia de internacionalização. Na terceira etapa aplicou-se a pesquisa de campo com os atores. Ao todo foram realizadas 10 entrevistas com oito GEFN entre 2017 e 2018 . A análise dos dados coletados foi realizada na última etapa com a transcrição das entrevistas, codificação dos textos conforme as características (formas de entrada, vantagens competitivas, estratégias e obstáculos), identificação de padrões, delineamento e verificação das conclusões.

Levou-se em consideração que os registros capturados nas respostas das entrevistas foram apenas uma parte da série total de evidências de estudo de caso. Sendo assim, além das entrevistas, os documentos obtidos no website das empresas, documentos recebidos pelos representantes das empresas, demais entrevistas das empresas concedidas aos veículos de mídia e demais estudos acadêmicos realizados com as mesmas empresas foram também agregados à análise.

As oito GEFN objetos deste estudo de caso possuem 100\% do capital controlado por acionistas brasileiros residentes no Brasil e são de estrutura familiar. As empresas estão em atividade por, 
no mínimo, 21 anos e, no máximo, 60 anos. As empresas empregam entre 430 a 6.500 funcionários e faturam entre $\mathrm{R} \$ 333,2$ milhões a $\mathrm{R} \$ 5,3$ bilhões, de modo que todas as empresas são de grande porte - receita superior a R\$ 300 milhões, segundo BNDES (2019). O investimento em $\mathrm{P} \& \mathrm{D}$ corresponde entre 3,5\% a $10 \%$ da receita, proporção semelhante a participação do pessoal ocupado em atividades de P\&D em relação ao total de empregados, que alterna entre $3,2 \%$ a $11,1 \%$. As oito empresas compreenderam, em conjunto, mais de $30 \%{ }^{4}$ do faturamento do mercado farmacêutico total, em 2016, e estão presentes em 82 dos 142 produtos aprovados nas Parcerias para o Desenvolvimento Produtivo (PDPs) ${ }^{5}$, entre 2009 a 2017 (Anvisa, 2017; MS, 2018).

\section{A dinâmica da expansão internacional das empresas farmacêuticas nacionais}

Os resultados da pesquisa de campo estão apresentados nas duas subseções seguintes.

\subsection{Estratégias e formas de entrada}

A inserção internacional iniciou na forma de exportações indiretas em pelo menos cinco das oito empresas pesquisadas ${ }^{6}$. As empresas denominam essas exportações como oportunistas, pois não partiram de uma estratégia da empresa, mas de uma demanda pontual de um cliente estrangeiro. A inserção internacional passou a fazer parte das estratégias das empresas a partir de 2000 e seguiram um processo contínuo. Conforme relatado por algumas empresas farmacêuticas nacionais que competem no mercado em medicamentos genéricos, este segmento não permitirá sustentar os seus crescimentos a longo prazo, pois é uma área que se concorre por preço e há grande penetração de produtos estrangeiros. Devido a tal perspectiva, as empresas encontraram alternativas para manter seu crescimento e participação no mercado brasileiro por meio da internacionalização. Por um lado, as empresas adotaram estratégias de acessar mercados nos quais seus medicamentos genéricos ainda sejam competitivos e, por outro, adotaram estratégias focadas no desenvolvimento de medicamentos mais inovadores. As empresas possuem quatro tipos de estratégias de internacionalização. O Quadro 2 sintetiza as características da internacionalização das GEFN pesquisadas em relação às formas de entrada e estratégias.

\footnotetext{
${ }^{4}$ Não compreende o faturamento de duas das empresas da amostra por motivos de sigilo.

${ }^{5}$ As Parcerias para o Desenvolvimento Produtivo (PDPs) foram implementadas com o objetivo de utilizar os laboratórios públicos para diminuir a dependência externa do setor de saúde e melhorar sua competitividade e capacitação tecnológica por meio da transferência de tecnologia entre as ETNs e empresas farmacêuticas nacionais e os laboratórios públicos (Torres, 2015).

${ }^{6}$ Não ficou totalmente claro, em algumas entrevistas, se os casos de exportação são indiretos.
} 
Quadro 1 - Formas de entrada e estratégias de internacionalização das grandes empresas farmacêuticas nacionais estudadas

\begin{tabular}{|c|c|c|c|c|}
\hline & Acesso a mercado & Acesso a recursos & Acesso a ativos estratégicos & Inovação estratégica \\
\hline Empresas & 8 & 7 & 6 & 3 \\
\hline $\begin{array}{l}\text { Forma de } \\
\text { entrada }\end{array}$ & $\begin{array}{c}\text { Exportação, licenciamento, } \\
\text { IDE }\end{array}$ & $\begin{array}{c}\text { Exportação, } \\
\text { licenciamento, IDE }\end{array}$ & Licenciamento e IDE & IDE \\
\hline $\begin{array}{l}\text { Início do } \\
\text { processo }\end{array}$ & 2005 & 2008 & 2012 & 2015 \\
\hline $\begin{array}{c}\text { Região/país de } \\
\text { destino }\end{array}$ & América Latina e África, & $\begin{array}{c}\text { Europa, América } \\
\text { Latina e do Norte e } \\
\text { China }\end{array}$ & $\begin{array}{c}\text { América Latina e do Norte, } \\
\text { Europa }\end{array}$ & EUA e China \\
\hline $\begin{array}{l}\text { Objetivo da } \\
\text { estratégia }\end{array}$ & $\begin{array}{l}\text { - Manter o crescimento da } \\
\text { empresa. } \\
\cdot \text { Aproximar-se de clientes. } \\
\text { · Marketing e } \\
\text { reconhecimento do produto. } \\
\text { - Agregar canais de } \\
\text { distribuição. } \\
\cdot \quad \text { Diversificar portfólio e } \\
\text { extensão do ciclo do produto } \\
\cdot \quad \text { Aproveitar capacidade } \\
\text { produtiva doméstica. }\end{array}$ & $\begin{array}{l}\text { Estratégia } \\
\text { complementar } \\
\cdot \text { Buscar matérias- } \\
\text { primas. } \\
\cdot \text { Obter fluxo em } \\
\text { moeda estrangeira. }\end{array}$ & $\begin{array}{l}\text { Buscar conhecimentos } \\
\text { tecnológicos. } \\
\cdot \text { Aprimorar as capacidades } \\
\text { de produção. }\end{array}$ & $\begin{array}{l}\text { - Buscar nichos de } \\
\text { mercado com } \\
\text { inovação radical. }\end{array}$ \\
\hline
\end{tabular}

Fonte: Elaboração própria com base na pesquisa de campo.

A estratégia de acesso ao mercado foi adotada por todas as GEFN pesquisadas, às vezes sendo o principal objetivo da inserção internacional. Embora as empresas já tivessem atividades internacionais há anos, as definições estratégicas de internacionalização foram feitas em 2005 (duas empresas), 2010 (uma empresa) e 2015 (duas empresas). As formas de entrada utilizadas para acessar o mercado foram exportações, relações contratuais via licenciamento e Investimentos Diretos Externos (IDE) direcionados aos países latino-americanos e africanos. A internacionalização por meio de exportações ou licenciamentos foi usada por todas as empresas para acessar o mercado internacional.

Um fator comum foi evidenciado em cinco empresas, cuja estratégia de internacionalização focada no acesso ao mercado esteve atrelada à estratégia de crescimento da empresa, foi o objetivo de estender o ciclo de vida dos produtos aos países menos desenvolvidos, no molde evidenciado por Vernon (1966). Para algumas empresas, a forma como a estratégia de acessar mercados foi implementada buscou o reconhecimento das marcas dos produtos e o investimento em marketing para aproximarem-se dos clientes. As empresas fizeram aquisição de empresas com marcas reconhecidas de medicamentos genéricos no mercado local, o que somou ao objetivo de agregar canais de distribuição, ou ainda investiram na formação destes canais nos mercados de destino das exportações. O estabelecimento de canais de distribuição teve grande importância nas estratégias das empresas, pois é um fator crítico à comercialização dos produtos da indústria farmacêutica e também por torná-las mais competitivas para licenciarem medicamentos de empresas de países desenvolvidos que procuram se inserir nos mercados da região.

Sete GEFN internacionalizaram para acessar recursos disponíveis em outros países. O recurso comum para tais empresas foram os IFAs. Todas as empresas pesquisadas são importadoras de IFAs, sendo que duas delas produzem cerca de 50\% destes recursos utilizados na produção. De modo geral, as empresas procuraram criar uma relação mais estreita com fornecedores internacionais, no sentido de ter exclusividade no fornecimento de IFAs. Porém, em nenhum dos 
casos o acesso a recursos foi a principal estratégia da inserção externa das empresas e esteve amparado nas outras estratégias de expansão internacional.

A internacionalização para acessar ativos estratégicos foi identificada em seis GEFN com o objetivo de buscar conhecimentos tecnológicos (quatro empresas) ou aprimorar as capacidades de produção (duas empresas), procurando melhorar as suas vantagens competitivas. As empresas buscaram conhecimentos tecnológicos para dar suporte ao desenvolvimento de medicamentos por meio de licenciamentos e comprando participações em empresas de P\&D e estabelecendo centros próprios de P\&D em países desenvolvidos. As empresas com estratégias de acessar ativos relacionados às capacidades de produção combinaram com a estratégia de acessar mercados. Assim, as empresas fizeram IDE - aquisição e compra de participação acionária - para acessar o portfólio das empresas estrangeiras e passar a atuar em um novo segmento.

A necessidade de desenvolver medicamentos inovadores para manter a competitividade no mercado, inclusive, no brasileiro levou três GEFN a adotarem inovação estratégica. Esta estratégia de internacionalização é característica das empresas dos países em desenvolvimento, as quais invés de adotarem uma estratégia de acessar ativos tecnológicos ou de acessar mercado, as empresas identificam lacunas - tal como novos segmentos, novas necessidades de clientes ou novas formas de produzir - na conjuntura da indústria farmacêutica e buscam preenchê-las para se tornarem líderes de um novo mercado (Mathews, 2006; Luo \& Tung, 2007). O objetivo das empresas com inovação estratégica é intensificar os esforços em inovação radical para se inserirem em segmentos com oportunidades inovadoras, em que há espaço para empresas do porte das GEFN competir. Esta foi a alternativa encontrada pelas empresas para se inserirem em segmentos mais lucrativos da indústria farmacêutica, uma vez que não teriam capacidade de desenvolver um medicamento inovador sozinhas, como as grandes empresas farmacêuticas mundiais ${ }^{7}$. Os nichos de mercado almejados são os medicamentos indicados às doenças específicas que não são alvos das grandes empresas farmacêuticas mundiais. A forma de inserção no mercado internacional foi por meio do investimento em empresas de pequeno e médio porte em países com reconhecida estrutura tecnológica na indústria farmacêutica, como EUA, e na China.

A forma como uma das empresas colocou em prática a inovação estratégica foi criando uma empresa que funciona como fundo de investimentos para captar recursos dos acionistas e investir em empresas de biotecnologia com projetos de inovações radicais em fase de desenvolvimento. Esta empresa fez investimentos diretos em 10 empresas de biotecnologia com inovação radical em doenças complexas, assim obtendo participação acionária e direito de comercializar seus produtos. Adicionalmente, a filial estrangeira também tem a função de registrar, no Food and Drug Administration (FDA), os medicamentos genéricos complexos e de inovação incremental produzidos no Brasil para a comercialização nos EUA. As outras duas empresas que fizeram inovação estratégica instalaram unidades de prospecção de novas pesquisas e novos produtos, especialmente, os inovadores, para serem pioneiras no licenciamento destes medicamentos no mercado brasileiro. Conjuntamente a essa estratégia, também aliaram o objetivo de dar suporte às relações de parceria com universidades, que as empresas têm no exterior.

7 O desenvolvimento de um medicamento inovador demanda, aproximadamente, 12 anos e um investimento de US\$ 1,9 bilhão, segundo as estimativas de Dimasi, Hansen e Grabowski (2003). 


\subsection{Vantagens competitivas e obstáculos}

As vantagens competitivas das GEFN que permitiram sua internacionalização foram classificadas em cinco tipos: específicas de propriedade, de localização, de internalização, conhecimento sobre a internacionalização e arranjo político-institucional-regulatório do Brasil. A ausência de alguma dessas vantagens se reflete na existência de obstáculos à internacionalização da mesma natureza. Desta forma, foram quatro conjuntos de obstáculos encontrados pelas GEFN na internacionalização: as vulnerabilidades do arranjo político-institucional-regulatório do Brasil, barreiras à entrada, distância psíquica e falta de experiência e conhecimento. O Quadro 3 relaciona as vantagens competitivas com os obstáculos da internacionalização das GEFN estudadas.

Quadro 2 - Vantagens competitivas e obstáculos de internacionalização das grandes empresas farmacêuticas nacionais estudadas

\begin{tabular}{|c|c|c|c|}
\hline \multicolumn{2}{|c|}{ Vantagens Competitivas } & \multicolumn{2}{|c|}{ Obstáculos } \\
\hline $\begin{array}{l}\text { 1. Vantagens } \\
\text { específicas de } \\
\text { propriedade }\end{array}$ & $\begin{array}{l}\text { Portfólio (diversidade e boa qualidade) } \\
\text { Aumento do porte - economias de escala e } \\
\text { recursos financeiros próprios } \\
\text { Capacidades criadas para atender as } \\
\text { exigências regulatória e legislativa } \\
\text { brasileiras }\end{array}$ & \multirow{3}{*}{ 1. Barreiras à entrada } & \multirow{3}{*}{ - Divergências regulatórias/PI } \\
\hline $\begin{array}{l}\text { 2. Vantagens de } \\
\text { localização }\end{array}$ & $\begin{array}{l}\text { Demanda a partir do cliente } \\
\text { Baixa distância psíquica } \\
\text { Potencial de crescimento do mercado } \\
\text { Qualidade regulatória } \\
\text { Ambiente inovador, empreendedor e } \\
\text { competitivo } \\
\text { Direitos de PI }\end{array}$ & & \\
\hline $\begin{array}{l}\text { 3. Vantagens de } \\
\text { internalização }\end{array}$ & $\begin{array}{l}\text { Evitar custos de transação } \\
\text { Apropriação de componentes intangíveis }\end{array}$ & & \\
\hline $\begin{array}{l}\text { 4. Conhecimentos } \\
\text { sobre } \\
\text { internacionalização }\end{array}$ & $\begin{array}{l}\text { Reconhecimento da importância da } \\
\text { internacionalização } \\
\text { Papel do empreendedor } \\
\text { Fontes de informação estrangeiras }\end{array}$ & $\begin{array}{l}\text { 2. Falta de experiência e } \\
\text { conhecimento } \\
\text { 3. Distância psíquica }\end{array}$ & $\begin{array}{l}\text { Falta de cultura } \\
\text { internacional } \\
\text { Divergências culturais }\end{array}$ \\
\hline $\begin{array}{l}\text { 5. Arranjo político- } \\
\text { institucional- } \\
\text { regulatório do Brasil }\end{array}$ & - Instrumentos não-financeiros & $\begin{array}{l}\text { 4. Vulnerabilidades no } \\
\text { arranjo político- } \\
\text { institucional-regulatório } \\
\text { brasileiro }\end{array}$ & $\begin{array}{l}\text { Desconhecimento sobre } \\
\text { políticas/instrumentos de } \\
\text { apoio } \\
\text { Problemas regulatórios }\end{array}$ \\
\hline
\end{tabular}

Fonte: Elaboração própria com base na pesquisa de campo.

Enquadram-se nas vantagens específicas de propriedade os atributos que a empresa pode criar ou comprar de outras instituições e, desta forma, ter direitos de propriedade sobre estes recursos. Elas podem derivar de da infraestrutura macroinstitucional do país da empresa (Dunning, 1988; 2006). A maior parte das empresas (cinco) relatou que o aumento dos seus portes fortaleceu as estratégias de internacionalização. $\mathrm{O}$ crescimento das empresas farmacêuticas nacionais, a partir da criação do segmento de medicamentos genéricos, foi importante para gerar a disponibilidade de recursos financeiros para realizar a inserção internacional, ressaltado por todas as empresas, e 
as economias de escala de produzir para o amplo mercado consumidor brasileiro, que assegurou preços competitivos no mercado internacional.

O portfólio de produtos com boa qualidade e diversidade foi apontado como uma vantagem competitiva por cinco empresas nas suas estratégias de acessar mercados. As capacidades produtivas e tecnológicas criadas a partir da adaptação das GEFN para atender as mudanças institucionais da Anvisa e da Lei dos Genéricos foram vantagens competitivas para a internacionalização. Segundo ressaltado pelas empresas, as exigências regulatórias da Anvisa são comparáveis às das agências de países desenvolvidos, como o FDA e European Medicines Agency (EMA). Além disso, muitos países na América Latina não exigem testes para certificar os medicamentos genéricos, assim, os medicamentos brasileiros têm qualidade superior às empresas concorrentes naqueles países.

Apesar da Anvisa vir fazendo um esforço para compatibilizar as suas exigências com a das maiores agências reguladoras mundiais ${ }^{8}$, as divergências regulatórias e de propriedade industrial, barreiras à entrada específicas do setor farmacêutico, foram apontados por cinco empresas como obstáculos à internacionalização. Uma das barreiras de ordem regulatória se refere aos dossiês exigidos no processo de registro do medicamento, que têm uma grande variação entre os países. Este processo demanda tempo e investimento da empresa que deseja acessar os mercados, sendo que, muitas vezes, os países estabelecem a necessidade de testes clínicos na população local. As empresas também relataram que as divergências regulatórias entre os países, geralmente, foram o obstáculo que barrou o processo de exportação, como foi o caso de uma empresa que deixou de vender aos EUA devido a restrições no marketing do produto.

As vantagens de localização se referem aos atrativos do mercado internacional para as empresas. Deste modo, depende do tipo de estratégia que a empresa adota. Para as empresas com estratégicas mais sofisticadas (acesso a ativos estratégicos e inovação estratégica), o ambiente inovador, com incentivo ao empreendedorismo e à formação de redes, característicos de países desenvolvidos, foram determinantes para a escolha do local de inserção. Assim, as empresas buscaram se inserir em sistemas nacionais de inovação que oferecem vantagens, como infraestrutura física, pessoal qualificado, sistemas regulatórios céleres e disponibilidade de recursos financeiros e investidores. Já para as empresas que adotaram a estratégia de acessar mercado, as vantagens de localização estavam relacionadas ao potencial de crescimento do mercado e à baixa distância psíquica dos países latino-americanos e africanos. A distância psíquica é definida por Johanson e Vahlne (1977) como os fatores que podem dificultar o fluxo de informações entre empresas de diferentes países, tais como idioma, nível de educação, práticas de negócios, cultura, desenvolvimento econômico e social, distância geográfica. Consequentemente, as divergências culturais entre países com grande distância psíquica foram

\footnotetext{
${ }^{8}$ Em 2016, a Anvisa passou a ser membro do International Conference on Harmonisation of Technical Requirements for Registration of Pharmaceuticals for Human Use (ICH). Esta organização é formada pelas principais autoridades reguladoras do mundo, como o FDA, EMA e a Pharmaceuticals and Medical Devices Agency (PMDA), do Japão. Como participante dos grupos de trabalho do ICH, a Anvisa se comprometeu a adequar-se, no prazo de cinco anos, aos cinco guias do $\mathrm{ICH}$, que se referem às ações de Farmacovigilância, Pesquisa Clínica, implementação do Common Technical Document (CTD) e do vocabulário do dicionário de terminologia médica (MedDRA). Isto significa que haverá uma padronização dos manuais da Anvisa aos moldes das agências reguladoras daqueles países (ANVISA, 2018)
} 
obstáculos às empresas com estratégias de acessar mercados. Este tipo de obstáculo pode ser amenizado com o acesso a informação e conhecimento por parte da empresa.

O conhecimento sobre internacionalização é um elemento crítico ao processo de inserção internacional, pois a habilidade organizacional de criar, absorver e armazenar o conhecimento pode ser uma importante fonte de vantagem competitiva da empresa (Teece, 2009). Um dos fatores mais importantes do conhecimento sobre a internacionalização é o reconhecimento do valor do mesmo (Cohen \& Levithal, 1990). Seis empresas demonstraram reconhecer que o mercado internacional é uma fonte de oportunidades e conhecimento, evidenciado pelas estratégias internacionais de longo prazo. Desta forma, a internacionalização foi vista pelas empresas como uma condição necessária para manter suas taxas de crescimento, sobretudo, por meio da inovação. O papel do empreendedor, em alguns casos representado pelo conselho administrativo das empresas, foi destacado por cinco empresas pela importância nas tomadas de decisão nas estratégias de internacionalização das empresas, especialmente, porque muitas vezes foram os idealizadores do processo. Em contrapartida, as empresas também apontaram que a falta de uma cultura internacional na organização, as quais são de estrutura familiar, foi um obstáculo à internacionalização.

O arranjo político-institucional-regulatório brasileiro mostrou-se, em alguns casos, como vantagens competitivas para a internacionalização das GEFN. Os instrumentos não-financeiros de incentivo à inserção internacional, representados pelo Programa Brazilian Pharma Solutions, coordenado pela Apex-Brasil e Abiquifi, foram os mais importantes na opinião das empresas. as empresas não demonstraram interesse pelos instrumentos financeiros de auxílio às exportações, como também, de financiamento da produção internacional, ofertados pelos BNDES, pois informaram terem recursos próprios disponíveis para realizar a inserção internacional. As ações ofertadas pelo Programa compreendem projetos compradores (trazendo potenciais compradores para conhecer as fábricas brasileiras), rodadas de negócios com as empresas brasileiras para buscar parcerias internacionais e promoção da imagem sanitária do Brasil no exterior, além da assistência para transferência de tecnologia, formação de parcerias com empresas estrangeiras para codesenvolvimento de produtos e inteligência comercial, identificando países-alvo para a inserção.

Apesar disso, quando solicitados a avaliar as políticas públicas de apoio à internacionalização de empresas farmacêuticas, nenhuma das empresas entrevistadas aferiu que os instrumentos existentes são suficientes. Nenhum ${ }^{9}$ deles também informou saber que a internacionalização estava na agenda da política industrial e desconhecem alguns dos instrumentos disponibilizados. Assim, o desconhecimento sobre as políticas/instrumentos de apoio à internacionalização são o principal obstáculo para a inserção internacional no que diz respeito às vulnerabilidades do arranjo político-institucional-regulatório brasileiro. Além desses, os problemas regulatórios referentes à padronização das normas da Anvisa ao modelo internacional, também foram destacados pelas empresas.

\footnotetext{
${ }^{9}$ Pergunta não realizada a uma empresa da pesquisa de campo.
} 


\section{Discussão dos resultados}

A investigação das características da internacionalização das empresas farmacêuticas nacionais encontrou que existem idiossincrasias no processo de expansão internacional das empresas pesquisadas. Além disso, também foi possível identificar que existem dois padrões de internacionalização, os quais agregam atributos específicos do processo de expansão internacional adotado pelas empresas.

A primeira característica comum a todas as GEFN pesquisadas foi a inserção internacional acelerada, padrão encontrado na internacionalização de empresas de países em desenvolvimentos (Luo \& Tung, 2006; Bonaglia \& Goldstein; Mathews, 2006). Assim como ocorre com empresas que entram tardiamente no mercado internacional, o aumento do compromisso e aprendizado que se desenvolveria gradualmente com a inserção em outros países foi substituído, ao menos em parte, pela evolução das TICs, que permitiram acelerar esse processo de obtenção de conhecimento, e pela liberalização dos fluxos de investimentos e mercadorias, que diminuiu as barreiras entre os países. Esse também foi um fator que influenciou a saída das empresas de países em desenvolvimento antes de estarem maduras em seus mercados (Dunning, Kim \& Park, 2008). Contudo, como evidenciado na pesquisa, as empresas farmacêuticas nacionais já operavam por muitos anos no mercado doméstico, no mínimo 20 anos, e eram líderes em faturamento no Brasil.

Portanto, a expansão internacional acelerada das empresas pode ser explicada por duas forças. Uma delas é o impacto da liberalização econômica, que influenciou a saída das empresas para reagir a concorrência internacional no mercado doméstico e manter suas taxas de crescimento. A outra está relacionada às vantagens competitivas que as empresas foram construindo ao longo do desenvolvimento industrial brasileiro. As GEFN sempre foram dependentes da tecnologia estrangeira, se desenvolveram por um longo período com reserva de mercado, sofreram com a abertura econômica abrupta e passaram por reformas regulatórias, sanitárias e de propriedade industrial rapidamente impostas. A truculência do ambiente competitivo brasileiro forçou as empresas farmacêuticas nacionais a desenvolverem capacidades, sobretudo, amparadas por políticas direcionadas ao setor, para sobreviverem e serem bem-sucedidas no mercado doméstico, que passaram por satisfazer uma demanda exigente e sensível aos preços, superar as incertezas institucionais e enfrentar a concorrência com as grandes empresas farmacêuticas transnacionais. Estas capacidades puderam, até certo ponto, serem convertidas em vantagens competitivas na expansão internacional. Kothari, Kotabe e Murphy (2013) identificaram o mesmo padrão em empresas internacionalizadas chinesas e indianas, as quais conseguiram transformar as desvantagens dos recursos não-competitivos (non-market resource disadvantages) do ambiente doméstico em vantagens na internacionalização.

Assim como também identificado em outras pesquisas sobre países em desenvolvimento (Luo \& Tung, 2007; Bonaglia \& Goldestein; Mathews, 2006; Martin \& Javalgi, 2016; Aguilera, et al., 2017), as características do mercado doméstico brasileiro (regulações e protecionismo por meio de tarifas e subsídios) permitiram o rápido crescimento e acumulação de recursos financeiros pelas empresas que puderam ser investidos na internacionalização, sobretudo, para aquelas que iniciaram com IDE. Por isso, foi uma vantagem competitiva destacada por todas as empresas da pesquisa. 
O ambiente institucional é um dos fatores que pode servir como promotor ou entrave à internacionalização, por este motivo está na agenda de desenvolvimento econômico de muitos países (Aguilera et al., 2017; Dunning, 2006). Na pesquisa realizada com as GEFN, as vulnerabilidades do arranjo político-institucional-regulatório brasileiro afetaram a internacionalização de todas elas. Em relação ao sistema regulatório brasileiro, a Anvisa afeta a internacionalização das empresas de forma dual. Por um lado, a sua criação e as medidas que vieram a partir de então contribuíram para melhorar as vantagens competitivas das empresas que construíram capacidades para adequarem-se aos processos de fabricação. Por outro lado, constatou-se que a morosidade na aprovação dos medicamentos, a falta de definição de prazos para a aprovação e pouca abertura para a comunicação com as empresas impactam a estratégia de internacionalização e de inovação das empresas que atuam no mercado brasileiro. Esta morosidade também interfere, em parte, na decisão de realizar desenvolvimento de medicamentos no mercado brasileiro pelas ETNs localizadas no Brasil. Este obstáculo também já foi apontado por Paranhos (2010) e, no entanto, ocorreram poucas mudanças desde então. Também cabe ressaltar que as normas da Anvisa ainda estão distantes das normas do ICH e o processo de padronização por parte da regulação parece andar a passos lentos, de modo que haverá pouco tempo para as empresas de adequarem até 2021.

Com relação ao desconhecimento das políticas e instrumentos de incentivo à internacionalização por parte das empresas, observa-se um forte desalinhamento entre os formuladores das políticas e as empresas. Uma vez que as empresas farmacêuticas nacionais estão buscando a expansão internacional para aprimorar suas capacidades produtivas e inovativas, é necessário que as políticas públicas estejam, não somente acompanhando, mas à frente do processo de internacionalização, planejando como este movimento pode trazer retornos positivos à indústria brasileira. Assim como alertou Perez (2008), cabem às políticas identificar o que se deseja ganhar com a inserção internacional e construir os caminhos para tal propósito.

\subsection{Exploração dos ativos e capacidades das empresas no mercado internacional}

As estratégias de internacionalização das GEFN de acessar mercados e de acessar ativos estratégicos relacionados às capacidades de produção, complementadas com as estratégias de acessar recursos, estiveram baseadas no motivo de explorar os ativos e capacidades da empresa. Estas empresas são grandes produtoras brasileiras de medicamentos genéricos e acessaram mercados em desenvolvimento, nos quais seus produtos ainda estavam na fase madura (Vernon, 1966), possibilitando a manutenção do crescimento do faturamento.

O principal atributo explorado no mercado internacional é o portfólio de medicamentos. A diversidade do portfólio e a qualidade dos medicamentos, atestados pelo rigor regulatório e legislativo brasileiro, foi um diferencial em relação aos concorrentes de países em desenvolvimento, possibilitando a inserção em países com processo regulatório mais simplificado que permitiam comercializar os produtos brasileiros sem a necessidade de registros no local. Este foi um movimento diferente daquele seguido na internacionalização das empresas farmacêuticas indianas, as quais procuraram se qualificar internacionalmente junto ao FDA e da Organização Mundial da Saúde. 
Conforme relatado pelas empresas que exploraram seus ativos e capacidades, a maioria das suas operações internacionais foi direcionada para os países da América Latina e África. No entanto, ao confrontar com os dados de comércio exterior da Secex/MDIC, nota-se que, grosso modo, metade das exportações brasileiras de produtos farmacêuticos é destinada aos países latinoamericanos e a outra metade aos países da Europa, EUA e Canadá. Uma proporção muito pequena das exportações é destinada aos países africanos, embora tenham sido destacados pelos entrevistados. O resultado corrobora com outros estudos (Perin \& Cario, 2019; Cuervo-Cazurra, 2008) que mostraram que as empresas brasileiras se internacionalizaram para acessar os mercados, majoritariamente, latino-americanos.

A exploração dos ativos e capacidades das GEFN no mercado internacional é afetada pelas divergências regulatórias entre as agências dos países. Sendo assim, a padronização às normas do ICH pode beneficiar as GEFN com estratégias de internacionalização para entrar em países desenvolvidos. No entanto, tal obstáculo irá permanecer nas inserções de países em desenvolvimento, principais focos desse grupo de empresas, que não seguem a padronização às normas do ICH. No mercado doméstico, as empresas também podem ter dificuldades de se adaptarem às normas do $\mathrm{ICH}$ e perderam participação frente às ETNs que já seguem esta padronização.

\subsection{Aprimoramento dos ativos e capacidades das empresas no mercado internacional}

A motivação de aprimorar seus ativos e capacidades esteve presente na internacionalização das GEFN com inovação estratégica e acesso a ativos estratégicos referente aos conhecimentos tecnológicos. Este tipo de expansão internacional fundamentou-se no objetivo principal de buscar nichos de mercado com inovação radical. As empresas possuíam portfólio, majoritariamente, de medicamentos genéricos ou genéricos de marca e buscaram o mercado internacional para entrar nos segmentos de maior valor adicionado da indústria farmacêutica.

Estas empresas buscaram a inserção internacional como uma forma de acelerar $o$ desenvolvimento de capacidades e recursos para aumentar a sua competitividade. Diversos estudos (Athreye \& Kapur, 2009; Guillén \& Garcéa-Canal, 2009, entre outros) já evidenciaram que as empresas de países em desenvolvimento entram em países desenvolvidos para acessar os conhecimentos e os recursos intangíveis e poder se beneficiar das possíveis sinergias do mercado. Da mesma forma, a rápida internacionalização por estas empresas é característica de empresas de países em desenvolvimento com estratégias de acessar tecnologias e conhecimento de países desenvolvidos (Kothari, Kotabe \& Murphy, 2013; Buckley, Elia \& Kafouros, 2014).

Parece adequado o resultado da pesquisa de que as empresas que internacionalizam motivadas pelo aprimoramento de capacidades e ativos foram as que mais elencaram vantagens competitivas relacionadas ao conhecimento sobre internacionalização. As empresas fizeram mudanças na estrutura organizacional - contratação de pessoal, criação de departamentos específicos para inovação radical e para internacionalização e mecanismos formais para compartilhamento interno do conhecimento gerado com a internacionalização - para aprimorar as capacidades de aprendizado nas suas jornadas de expansão externa.

Não obstante os esforços realizados, cabe considerar que para aprender com as atividades internacionais de modo a influenciar o desempenho inovativo é necessário que a empresa possua 
capacidade de absorção para capturar os transbordamentos tecnológicos existentes (Filippetti, Frenz, \& Ietto-Gillies, 2017). No que tange à capacidade inovativa das GEFN ${ }^{10}, 81,5 \%$ fizeram inovações de produto sozinhas, 49\% adquiriram P\&D externa e 30\% adquiriram outros conhecimentos externos, entre 2012 e 2014(Paranhos et al., 2018). Tais empresas investiram $0,9 \%$ das suas receitas líquidas de vendas na aquisição de P\&D externa e 4,9\% na aquisição de P\&D interna, entre 2012 e 2014. Paranhos et al. (2018) também constatou que as mesmas estão ampliando os esforços em estratégias de inovação mais sofisticadas, a partir da criação de departamentos de inovação radical, realização de comitês científicos e estratégias de internacionalização tecnológica. Tais empresas aumentaram significativamente as inovações de produtos completamente novos para a empresa para o mercado nacional $(150 \%$ entre 2008 e 2011) e para o mercado mundial (400\% entre 2008 e 2011) (Paranhos, Mercadante \& Hasenclever, 2016).

Pelo conjunto de informações observadas, constata-se que as empresas farmacêuticas nacionais empregam esforços inovativos e de absorção do conhecimento gerado. No entanto, estes esforços ainda são incipientes e parecem estar crescendo concomitantemente à expansão internacional. Segundo Cohen e Levinthal (1990), a capacidade de absorção do conhecimento novo gerado pelas empresas no mercado internacional depende da sua capacidade de absorção construída em momento anterior ao processo de internacionalização. Assim ocorreu em com a internacionalização de empresas chinesas e indianas, as quais se desenvolveram em ambientes domésticos com fraca oferta tecnológica. Para superar o atraso tecnológico, as empresas se associaram estrategicamente, nos mercados domésticos, com ETNs de países avançados para desenvolverem habilidades específicas ou alavancarem nichos de mercado, ao mesmo tempo que deslocavam parte significativa do desenvolvimento tecnológico para o exterior. Em momento posterior, tais empresas adotaram a estratégia de encontrar novos nichos de mercado e, simultaneamente, investir em inovação, tornando assim uma vantagem competitiva nos países desenvolvidos (Kothari, Kotabe \& Murphy, 2013).

Entretanto, esta não foi uma possibilidade para as GEFN, que teve ambiente marcado por uma competição perversa, em que as ETNs farmacêuticas se mantiveram operando na parcela dos produtos mais sofisticados e não desenvolveram as atividades mais sofisticadas tecnologicamente no Brasil, como P\&D local, formação de fornecedores, interações com ICTs nacionais, assim incapacitando as empresas farmacêuticas nacionais de receberem transbordamentos tecnológicos significativos. A interação entre as ETNs e as empresas farmacêuticas nacionais influencia o curso dos investimentos internacionais do país (Narula \& Dunning, 2010). No caso do Brasil, a baixa interação com relações de parcerias ajuda a explicar porque as empresas farmacêuticas nacionais entraram tardiamente no mercado internacional.

\footnotetext{
${ }^{10}$ A amostra de grandes empresas farmacêuticas nacionais inovadoras da Pintec de 2014 é composta por 24 empresas, representando $85,3 \%$ do total de grandes empresas farmacêuticas na pesquisa.
} 


\section{Conclusão}

Os resultados encontrados na pesquisa mostraram que a internacionalização pode ser uma oportunidade das GEFN aumentarem sua participação no mercado farmacêutico mundial, diminuindo o déficit comercial do setor, acessando conhecimentos essenciais para o processo inovativo e entrando em segmentos de maior valor agregado da indústria. No entanto, permanecem algumas preocupações relacionadas às motivações da internacionalização.

As GEFN motivadas pela exploração dos seus ativos e capacidades na expansão internacional seguem estratégias de acessar os mercados de países em desenvolvimento. Estas empresas estão explorando as suas vantagens competitivas construídas no mercado doméstico, ao mesmo tempo, obtêm certos ganhos de conhecimento ao lidar com mercados, consumidores, legislações e regulações diferentes. Contudo, assim como alertado por Patel e Pavitt (1990) a internacionalização feita para explorar as capacidades da empresa está apenas interessada em aumentar a rentabilidade da empresa no curto prazo, sem tentar melhorar seu capital tecnológico por intermédio do investimento. De fato, a internacionalização parece ser uma alternativa encontrada para manter a taxa de crescimento destas empresas, mas tem de se ter em conta que as vantagens da empresa no mercado internacional também podem se esgotar, pois são relacionadas aos medicamentos genéricos.

Do lado das GEFN motivadas a aprimorar ativos e capacidades, entende-se que suas estratégias não terão efeito se não houver capacidade de absorver o conhecimento gerado no exterior nas empresas domésticas. As empresas mostraram estar construindo capacidades dinâmicas, articulando suas capacidades e vantagens com a estratégia de crescimento e de internacionalização. Contudo, no que se refere aos benefícios futuros da internacionalização, não se pode afirmar que as empresas entrarão na competição de medicamentos inovativos, uma vez que a posse de capacidades dinâmicas não significa ter resultados de inovação, ainda que seja uma condição para sua geração (Barcelos, 2017). A localização das operações de P\&D e marketing em países desenvolvidos também permite aumentar sua capacidade de absorção (Zahra \& George, 2002). Contudo, a P\&D interna aumenta ainda mais as capacidades locais de absorção (Cohen \& Levinthal, 1990), permitindo desenvolver os conhecimentos e o know-how essenciais para o desenvolvimento de novos produtos e inovação (Kogut \& Zander, 1993). A internacionalização motivada pelo aprimoramento tecnológico é importante para inserir as empresas nacionais no mercado farmacêutico internacional. Se as empresas conseguirem criar capacidades de absorver e aprender o que está sendo realizado no núcleo de inovações da

indústria farmacêutica mundial, poderá aproveitar uma futura janela de oportunidade para o catching-up (Lee \& Malerba, 2017), a exemplo de como foi realizado pelas indústrias de biotecnologia da Coreia do Sul.

\section{Agradecimentos}

O presente trabalho foi realizado com apoio da Coordenação de Aperfeiçoamento de Pessoal de Nível Superior - Brasil (CAPES) (Código de Financiamento 001) e do Conselho Nacional de Desenvolvimento Científico e Tecnológico $(\mathrm{CNPq})$, como resultado parcial do Projeto "Reflexo das políticas industriais e tecnológicas na saúde brasileiras na produção local e no fornecimento 
ao Sistema Único de Saúde (SUS)" apresentado à chamada MCTI/CNPq/CTSaúde/MS/SCTIE/Decit nº 41/2013 Rede Nacional de Pesquisas sobre Política de Saúde.

\section{Referências}

Agência Nacional De Vigilância Sanitária - Anvisa (2018). Disponível no: $<$ http://portal.anvisa.gov.br/>. Vários Acessos.

Agência Nacional De Vigilância Sanitária - Anvisa (2017). Anuário Estatístico do Mercado Farmacêutico. Brasília: Anvisa.

Aguilera, R. V., Ciravegna, L., A. C.-C., \& Gonzalez-Perez, M. A. (2017). Multilatinas and the internationalization of Latin American firms. Journal of World Business, 52, 447-460.

Athreye, S. \& Kapur, S. (2009). The internationalization of Chinese and Indian firms: trends, motivations and strategy. Industrial and Corporate Change, 18 (2), 209-221.

Banco Nacional de Desenvolvimento Econômico e Social - BNDES (2019). Disponível no: $<$ https://www.bndes.gov.br $>$. Acesso em mai. 2019.

Barcelos, R. (2017). A dinâmica das capacidades: elementos para a gestão estratégica. Revista Eletrônica Gestão e Sociedade, 11(30), 1934-1962.

Barroso, L. C. (2014). Esforços tecnológicos das firmas transnacionais no Brasil: um estudo da primeira década dos anos 2000. PPGE/IE/UFRJ. (Tese de doutorado).

Bonaglia, F., Goldstein, A., \& Mathews, J. A. (2007). Accelerated internationalization by emerging markets multinationals: The case of the white goods sector. Journal of World Business, 42, 369-383.

Buckley, P. J., Elia, S., \& Kafouros, M. (2014). Acquisitions by emerging market multinationals: Implications for firm performance. Journal of World Business, 49 (4), 611-632.

Carlsson, B. (2006) Internationalization of Innovation Systems: a survey of the literature. Research Policy, 35, 56-67.

Cohen, W. \& Levinthal, D. (1990). Absorptive capacity: a new perspective on learning and innovation. Administrative Science Quartely, 35 (1), 128-152.

Conti, C. R., Parente, R., \& Vasconcelos, F. C. (2016). When distance does not matter: Implications for Latin American multinationals. Journal of Business Research, 69, 19801992.

Cuervo-Cazurra, A. (2008). The multinationalization of developing country MNEs: The case of multilatinas. Journal of International Management, 14 (2), 138-154.

Dimasi, J. A., Hansen, R. W. \& Grabowski, H. G. (2003). The price of innovation: new estimates of drug development costs. Journal of Health Economics, 22, 151-185.

Dunning, J. (2006). Towards a new paradigm of development: implications for the determinants ofinternational business. Transnational Corporations, 15 (1), 173-227. 
Dunning, J., Kim \& Park.(2008). Old wine in new bottles: a comparison of emerging-market TNCs today and develop-country TNCs thirty years ago. In: Sauvant, K. The rise of transnational corporations from emerging markets: threat or opportunity? Edward Elgar Publishing, 158-180.

EvaluatePharma (2018). World Preview 2018, Outlook to 2024. Evaluate. [S.1.], p. 47.

Fialho, B. (2005). Dependência Biotecnológica e Biodiversidade: Um estudo histórico sobre a indústria farmacêutica no Brasil e nos Estados Unidos. Rio de Janeiro: COPPE/UFRJ. (Tese de Doutorado).

Filippetti, A., Frenz, M., \& Ietto-Gillies, G. (2017). The impact of internationalization on innovation at countries' level: the role of absorptive capacity. Cambridge Journal of Economics, 41, 413-439.

Gomes, E. Clusters e biotecnologia para a superação da imitação: estudo de caso da indústria farmacêutica brasileira. Rio de Janeiro: PPED/IE/UFRJ. (Tese de Doutorado), 2014.

Guillén \& Garcia-Canal. (2009). The American Model of the Multinational Firm and the "New" Multinationals From Emerging Economies. Academy of Management Perspectives, 2335 .

Hasenclever, L. et al. (2008). Diagnóstico e papel dos laboratórios públicos na capacitação tecnológica e atividades de P\&D da indústria farmacêutica brasileira. In: BUSS, P. M. ; 118 Carvalheiro, J. R. ; Casas, C. P. R. (Orgs.). Medicamentos no Brasil: inovação e acesso. Rio de Janeiro: Fiocruz, 2008.

Hasenclever, L. et al. (2018). Vulnerabilidades do Complexo Industrial da Saúde: reflexos das políticas industrial e tecnológica na produção local e assistência farmacêutica. Rio de Janeiro: E-papers.

IEDI. (2016). Panorama mundial e brasileiro do setor farmacêutico.

Instituto Brasileiro de Geografia e Estatística - IBGE. (2016). Pesquisa Industrial de Inovação Tecnológica 2014. Rio de Janeiro: IBGE.

Kogut, B. \& Zander, U. (1993). Knowledge of the firm and the evolutionary theory of the multinational corporation. Journal of International Business Studies, 4, 625-645.

Kothari, T., Kotabe, M., \& Murphy, P. (2013). Rules of the Game for Emerging Market Multinational Companies from China and India. Journal of International Management, 19, 276-299.

Lee, K., \& Malerba, F. (2017). Catch-up cycles and changes in industrial leadership: Windows of opportunity and responses of firms and countries in the evolution of. Research Policy, 46, 338-351.

Luo, Y., \& Tung, R.(2007); International expansion of emerging market enterprises: A springboard perspective. Journal of International Business Studies, 38, 481-498.

Mathews, J. (2006). Dragon multinationals: new players in 21st century globalization. Pacific J Manage, 23, 5-27.

Marconi, M. A., \& Lakatos, E. M. (2016). Fundamentos de metodologia científica. 7a. ed. São Paulo: Atlas. 
Martin, S. L. \& Javalgi, R. (2016). Entrepreneurial orientation, marketing capabilities and performance: The Moderating role of Competitive Intensity on Latin American International New Ventures. Journal of Business Research, 69 (6), 2040-2051.

Mckelvey, M. \& Orsenigo, L. (2001). Pharmaceuticals as a Sectoral Innovation System. Paper prepared for the ESSY Project (European Sectoral Systems of Innovation) and within the Epris Project.

Narula, R., \& Dunning, J. (2010). Multinational enterprises, development and globalization: some. Oxford Development Studies, 38 (3), 263-287.

Paranhos, J. (2010). Interação entre Empresas e Instituições de Ciência e Tecnologia no Sistema Farmacêutico de Inovação Brasileiro: estrutura, conteúdo e dinâmica. Rio de Janeiro: PPGE/IE/UFRJ. (Tese de doutorado).

Paranhos, J., Perin, F. S., Mercadante, E., \& Soares, C. (2018). Estratégias de inovação das grandes empresas farmacêuticas nacionais na interação empresa-ICT. Acesso em 01 de nov de 2018, disponível em Anais do III Encontro Nacional de Economia Industrial e Inovação: https://www.proceedings.blucher.com.br/article-list/enei2018-308/list\#articles

Perin, F. \& Cario, S. (2019). Capitalist Development Compared: A study of the pattern of the Brazilian and South Korean Outward Foreign Direct Investment. Análise Econômica, no prelo.

Radaelli, V. A inovação na indústria farmacêutica: forças centrípetas e forças centrífugas no processo de internacionalização. Campinas: IGE/UNICAMP, 2006. (Dissertação de Mestrado).

Sindusfarma.(2018) Sindicato da Indústria de Produtos Farmacêuticos no Estado de São Paulo. Indicadores econômicos. Disponível no: $<\underline{w w w}$.sindusfarmacomunica.org.br $>$. Acesso em jan. 2019.

Teece, D. J. (2009). Dynamic Capabilities \& strategic management: organizing for innovation and growth. Reino Unido: Oxford University Press.

Torres, R. L. (2015). Capacitação tecnológica na indústria farmacêutica brasileira. 2015. 212 f. Tese (Doutorado) - Curso de Programa de Pós-graduação em Economia, Instituto de Economia, Universidade Federal do Rio de Janeiro, Rio de Janeiro.

Tigre, P., Nascimento, C., \& Costa, L. (2016). Janelas de oportunidades e inovação tecnológica na indústria brasileira de medicamentos. Cad. Saúde Pública, 32, 1-12.

Vernon, R. (1966). International investment and international trade in the product cycle. Quarterly Journal of Economics, 80, 190-207.

Zahra, S. \& George, G. (2002). Absorptive Capacity: a review, reconceptualization, and extension. Academy of Management Review, 27 (2), 185-203. 